\title{
A Review of Current and Future Management of Geographic Atrophy
}

Riccardo Sacconi · Eleonora Corbelli · Lea Querques •

Francesco Bandello · Giuseppe Querques

Received: February 28, 2017 / Published online: April 8, 2017

(C) The Author(s) 2017. This article is an open access publication

\section{ABSTRACT}

Age-related macular degeneration (AMD) is a multifactorial disease and a leading cause of vision impairment in elderly people in Western society. Geographic atrophy (GA), the late stage of dry AMD, is typically defined as a round or oval area of atrophy of $175 \mu \mathrm{m}$ or more. In GA patients, visual acuity (VA) can still be good if the macula is spared, but decreased if GA extends through the fovea causing a great impairment of quality of life. Because of a poor correlation between VA and GA lesions or progression, a multimodal imaging approach is necessary to better follow up GA patients. In the last years, the introduction in clinical practice of new non-invasive tools such as fundus autofluorescence, structural optical coherence tomography (OCT) and OCT angiography helped the ophthalmologists to better

Enhanced content To view enhanced content for this article go to http://www.medengine.com/Redeem/ 8B08F060682C7A0C.

R. Sacconi - E. Corbelli - L. Querques - F. Bandello ·

G. Querques $(\bowtie)$

Department of Ophthalmology, University

Vita-Salute, IRCCS Ospedale San Raffaele, Milan, Italy

e-mail: giuseppe.querques@hotmail.it

R. Sacconi

Department of Ophthalmology, University of

Verona, University Hospital of Verona, Verona, Italy understand the natural course of GA patients. However, several pathways concerning the pathogenesis of the disease are not completely clarified yet and should be investigated further. Although no approved therapy exists for GA, healthy lifestyle and nutritional intervention with some specific supplementations (e.g., vitamins $\mathrm{C}$ and $\mathrm{E}$, beta-carotene, high dietary folate) may help to prevent the onset and to delay the progression of the disease. At the same time, several drugs are under evaluation in clinical trials with interesting results. These drugs try to stop several pathways implicated in the pathogenesis of GA, but probably only a few of these will prove truly effective, confirming the preliminary results, and will be available in clinical practice.

Keywords: Age-related macular degeneration; Antiinflammatory drugs; Dry-AMD; Geographic atrophy; Management; Neuroprotection; Nutritional supplements; Stem cell-based therapy; Vasodilators

\section{INTRODUCTION}

Age-related macular degeneration (AMD), a multifactorial disease, is a leading cause of vision impairment in elderly people in Western society [1-3]. Although the exact pathophysiological mechanisms behind the disease are not 
yet clear, several genetic and environmental risk factors were associated with AMD, such as age, cigarette smoking, blood hypertension, high lipid levels, abdominal obesity, dietary fat and low physical activity [4-7]. AMD is classified in dry AMD (d-AMD) or neovascular AMD (n-AMD) depending on the presence of choroidal neovascularization (CNV) [8, 9]. Geographic atrophy (GA) represents the late stage of d-AMD and is typically defined as a round or oval area of $175 \mu \mathrm{m}$ or more at fundus photography [10]. Due to the atrophy of outer retinal layers and retinal pigment epithelium (RPE), choroidal vessels are well visible at fundus examination. The incidence of GA in people of 85 years old is almost four times of n-AMD, and GA affects up to $22 \%$ of 90 -year-old people $[11,12]$. Visual acuity (VA) can still be good if the macula is spared, but decreased if GA extends through the fovea.

In the last years, several new non-invasive tools were developed and used to follow up GA patients, such as fundus autofluorescence (FAF), optical coherence tomography (OCT) and OCT angiography (OCT-A). Nevertheless, no approved treatment for GA is available, because no therapy is able to repair the impaired RPE and outer retinal layers. A great number of new therapies are under investigation preventing or interrupting the development of the atrophy.

In this review, we focused the attention on diagnosis and management of patients affected by GA and also on current data about drugs under investigation in the treatment of this disease. This article is based on previously conducted studies and does not involve any new studies of human or animal subjects performed by any of the authors.

To identify the publications concerning geographic atrophy, a systematic literature search of the MEDLINE/PubMed database (http://www.ncbi.nlm.nih.gov/pubmed) was performed in February 2017, using the following search strategy: "geographic atrophy" or "age related macular degeneration" in combination with management, outcome, quality of life, diagnosis and treatment. Additional literature was derived from the reference lists of identified publications. An additional systematic literature search of the Clinical Trials (https://clinicaltrials.gov) was performed using "geographic atrophy" as keyword.

\section{CURRENT MANAGEMENT AND PREVENTION OF GA}

Contrary to n-AMD, characterized by acute vision loss and anatomical and functional improvement after treatment, GA is a slowly but inexorably progressive disease that causes irreversible blindness over time [13]. Although no significant cure exists yet for GA, healthy lifestyle and nutritional intervention may help to prevent the onset and to delay the progression toward n-AMD [14]. Chiu et al. [15] demonstrated that overall dietary pattern is significantly associated with the risk of development AMD. Furthermore, several clinical studies reported that some supplementations seem to reduce the progression of d-AMD.

High doses of antioxidant vitamin (vitamins C, E and beta-carotene) and zinc supplements are found to produce a beneficial effect in slowing the progression of d-AMD [16]. Also a high dietary folate intake seems to reduce the risk of progression to GA, although this effect may be modified by the genetic profile related to C3 R102G [17].

In the absence of any treatment and because of a poor correlation between best corrected visual acuity (BCVA) and GA lesions or progression, a multimodal imaging approach is necessary to better follow up GA patients. Fundus photography has traditionally documented GA lesions as an abrupt transition of fundus pigmentation resulting from the atrophy of RPE cells [12]. Sharp margins, with a round or oval shape, and visible choroidal vessels are the main features of GA photographic definition [10].

However, FAF currently represents the gold standard for monitoring progressive GA enlargement, allowing a more reproducible measure of atrophic areas and a better lesion boundary discrimination. The loss of RPE autofluorescence indicates disruption of the functional interaction between RPE and photoreceptor cells due to damage or death of photoreceptors and/or RPE cells [18] (Fig. 1). Moreover, different patterns of increased FAF 


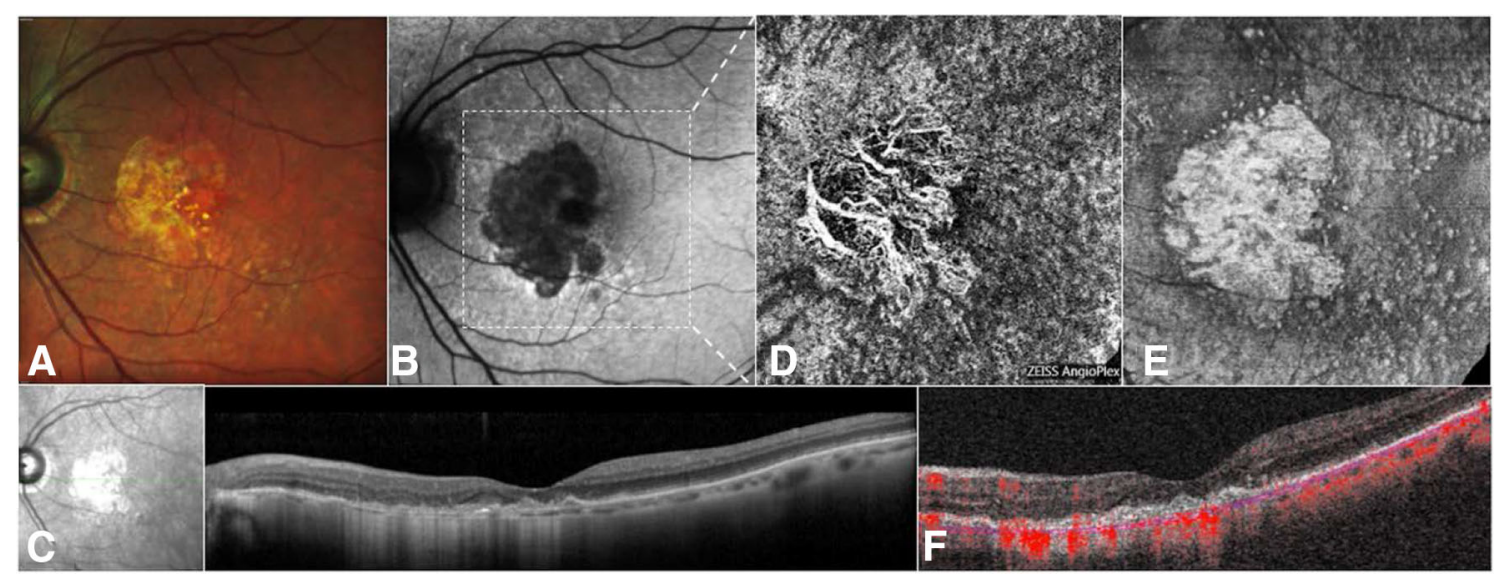

Fig. 1 Multimodal imaging of a patient affected by geographic atrophy (GA). Multicolor imaging (a) and fundus autofluorescence (b) showing the area affected by GA. c Combined infrared reflectance and structural optical coherence tomography (OCT) horizontal B-scan passing through the fovea showing the loss of photoreceptors,

outside patches of GA have been reported as prognostic markers for the subsequenct evolution [19]. Schmitz-Valckenberg et al. [20] estimated a median overall enlargement rate of $1.72 \mathrm{~mm}^{2} /$ year using FAF.

Also structural OCT is an available tool for the evaluation of the atrophic and junction areas of patients with GA (Fig. 1). The main microstructural alterations showed by OCT are thinning of hyperreflective external bands due to attenuation of the photoreceptors, ellipsoid zone and RPE/Bruch's complex as well as deeper hyperreflectivity in the sub-RPE layers because of loss of RPE and thus increased laser light penetration in the choroid [21]. Furthermore, different retinal findings have been described by means of OCT in GA areas such as the outer retinal tubulations (ORTs) [22], retinal pseudocysts [23], wedge-shaped subretinal hyporeflective lesions [24], crown-like elevations and ghost drusen [21]. In addition, peculiar OCT findings have been found also in the choroid of some eyes with GA and called choroidal caverns [25] and choroidal round hyporeflectivities [26].

More recently, OCT-A has added new data to define GA, providing a qualitative and quantitative analysis of the vascular network. Loss of choriocapillary flow has been detected by ellipsoid zone and retinal pigment epithelium/Bruch's complex with a backscattering effect in the area affected by GA. Choriocapillaris segmentation on $6 \times 6$ OCT-angiography $(\mathbf{d})$, corresponding en-face OCT (e) and B-scan with flow (f) showing the loss of choriocapillaris flow in the area affected by GA

OCT-A under the atrophic patches, while asymmetric alteration of choriocapillary has been showed at the margins of GA [27] (Fig. 1).

Thus, multimodal imaging is an indispensable approach to detect the retinal damages of GA patients, for documenting the natural history and for evaluating possible treatment responses in ongoing clinical trials.

\section{PATIENT QUALITY OF LIFE}

GA typically manifests as both moderate and severe central visual loss, associated with impairment of quality of life (QoL) [28]. In the early stages of GA, when the disease is limited to the extrafoveal area, patients often complain of symptoms from visual deterioration such as delayed dark adaptation, reduced contrast sensitivity, and dense and irreversible parafoveal scotomas with difficulty recognizing familiar faces and to read. They may be able to see only a part of words with a decrease in reading rate [29]. In the later stages, when the atrophy includes the parafoveal and foveal regions, a severe deterioration in central visual acuity occurs, and the patients experience symptoms such as distorted vision, trouble discerning colors, a slow recovery of visual function after 
exposure to bright light, a loss of contrast sensitivity and marked visual impairment in dimly lit environments, with limits in key aspects of daily life [30]. The major difficulties are related to driving, shopping alone, reading, finding street signs and a wide range of social and manual activities that require fine motor control. It is obvious that patients with both eyes affected are more limited in carrying out activities of daily living than those with only one eye affected.

However, quality of life of patients with GA does not only depend on visual acuity. Indeed, they have high risk of developing clinical depression derived from patients' inability to take care of themselves and from interference of visual loss with life in general [31]. Interestingly, depression more frequently afflicts patients with monolateral blindness than those with bilateral disease, maybe because of the fear of losing central vision in the eye not affected in the first ones and the resignation concerning the condition in the second ones [32]. Furthermore, they are more stressed than people of similar age; instead, they have a level of emotional distress comparable to that of people with disabling chronic illness (e.g., arthritis, acquired immunodeficiency syndrome, chronic obstructive pulmonary disease and bone marrow transplant) [32]. Thus, it is important to define QoL considering the impact of visual loss and the patient's ability to accept the disease.

In addition to increased susceptibility to depression, fear, anxiety and social isolation, patients GA are more predisposed to falls with high risks of fractures caused by poor vision [33].

An efficient measure of the change of QoL over time has been provided by means of questionnaires. The National Eye Institute Visual Function Questionnaire (NEI-VFQ), often used in clinical trials, is considered the gold standard to evaluate the impact of vision loss on patients' daily lives and QoL [34].

It is not easy to define QoL in patients affected by GA because it depends on many factors including physical, mental and social aspects that worsen the existing disability. Behavioral interventions may benefit emotional health and should be considered as part of the management of GA.

\section{PRESENT AND FUTURE OF GA TREATMENT}

At the current time, no therapy is approved for the treatment of GA, because no therapy is able to restore impaired RPE or outer retinal layers. However, several pathways have been implicated in the pathogenesis of d-AMD (e.g., oxidative stress, neuroprotection, chronic inflammation, complement activation and choroidal blood flow insufficiency) [35], and many drugs are under evaluation. In this section, we briefly report the most promising drugs under study in each category.

\section{Nutritional Supplementation}

The AREDS study evaluated the role of a specific supplementation formula (a daily dose of $80 \mathrm{mg}$ zinc oxide, $2 \mathrm{mg}$ cupric oxide, $15 \mathrm{mg} \beta$-carotene, $500 \mathrm{mg}$ vitamin $\mathrm{C}$ and $400 \mathrm{IU}$ vitamin $\mathrm{E}$ ) in the different stages of d-AMD [36]. This formula supplementation was not proven effective in reducing the grow rate of GA, probably because of the relatively small sample of GA patients included in the study. AREDS and AREDS2 supplementation has proven efficacy only in some patients affected by d-AMD, such as high-risk patients, significantly reducing the risk of AMD progression [36, 37]. However, several other supplementations will be evaluated in the treatment of GA because of the growing interest in this field. In fact, in the last years, many researchers have been evaluating the association between vitamin supplements and the genetic risk profile of many diseases with promising results [38].

\section{Neuroprotection}

The neuroprotection is thought to play an important role in AMD. There are two main drugs in development with interesting results: brimonidine and ciliary neurotrophic factor-501 (CNFT). Brimonidine is an $\alpha-2$ agonist generally used in ophthalmology for the treatment of glaucoma patients. However, this drug also showed a neuroprotective effect on retinal cells of rats [39] and thus is now under study in 
d-AMD patients. A randomized phase II study (NCT00658619) evaluated the efficacy of brimonidine on 119 patients with bilateral GA. The patients were divided in three groups (200 or $400 \mu \mathrm{g}$ of drug or a sham group) and injected with an intravitreal biodegradable polymer matrix similar to the dexamethasone intravitreal implant model (Ozurdex; Allergan, Irvine, CA, USA) [40]. Since the results were equivocal, a second study (NCT02087085) is underway with a larger sample to evaluate the effect of brimonidine in GA patients up to a 24-month follow-up.

Also CNTF, an IL-6 cytokine, has shown a protective effect on retinal cells in animal models [41]. CNTF, combined with a sustained-release platform (NT-501), showed a slowdown of the visual loss progression at 1-year follow-up in patients affected by GA in a randomized phase II clinical study (NCT00447954). The effects on VA stabilization seem to be related with the dose of the CNTF injected and with the increase of retinal thickness at structural OCT [42].

\section{Antiinflammatory Drugs}

Chronic inflammation has an important part in the development of GA, and corticosteroids could play a crucial role because of their antinflammatory effects $[43,44]$. Iluvien (Alimera Sciences, Alpharetta, GA, USA), a sustained-release formulation of fluocinolone acetonide, is under investigation in a randomized phase II study (NCT00695318) on 40 GA patients, but the results are not yet available.

Another promising target is the complement cascade because of its role in controlling inflammation also in d-AMD [45, 46]. Several complement inhibitor drugs are being investigated for the treatment of GA, but none has been approved yet. A phase II clinical trial (NCT02288559) demonstrated the effects of lampalizumab, a humanized monoclonal antibody (FCFD4514S; Genentech/Roche, San Francisco, CA, USA), in slowing down the progression of GA. Two phase III clinical trials [Chroma (NCT02247479) and Spectri
(NCT02247531)] are underway to confirm these results.

Another target involved in the progression of GA is amyloid beta. GSK933776 (GlaxoSmithKline, Brentford, UK) and RN6G (Pfizer, New York, NY, USA), two humanized monoclonal antibodies, are under investigation in two different phase II clinical trials (NCT01577381 and NCT01342926, respectively). However, the results are not yet available.

Many other antiinflammatory agents have completed various phase I clinical trials and now are under investigation in phase II/III studies to evaluate the long-term efficacy and safety. One of these drugs is ARC1905 (Zimura; Ophthotech Corp., Princeton, NJ, USA), an anti-C5 aptamer targeting $\mathrm{C5}$, which was demonstrated safe in a phase I study (NCT00473928). Another one is POT-4 (Potentia Pharmaceuticals, Louisville,Ky., USA and ALcon, Hünenberg, Switzerland), a C3 inhibitor, whose safety was confirmed in a phase I study (NCT00473928).

\section{Vasodilators}

Several vasodilators, such as alprostadil, MC-1101, moxaverine and sildenafil, are under investigation in the treatment of d-AMD. The rationale is that choroidal blood flow is diminished in elderly patients and thus blood flow restoration agents could play a crucial role in improving choroidal circulation and delaying the progression of d-AMD.

Alprostadil (UCB Pharma, Berkshire, UK) is the most promising drug in this category. In a randomized, phase III clinical trial (NCT00619229), alprostadil was more effective in slowing down the progression of visual loss than placebo in the treatment of d-AMD patients after 6 months of therapy [47]. Also MC-1101 showed promising results in a small phase I clinical trial (NCT01922128), demonstrating an increased choroidal blood flow after the treatment. Nevertheless, also for these drugs, further clinical trials are required to confirm the preliminary results and to establish their role in the treatment of GA. 
Other vasodilators such as Sildenafil (Viagra; Pfizer Inc., New York, NY, USA) and moxaverine, a nonselective phosphodiesterase inhibitor, showed unclear results in the treatment of $\mathrm{d}-\mathrm{AMD}$, and thus their future is still undetermined $[48,49]$.

\section{Other Therapies}

Other drugs are underway in the treatment of GA. Emixustat (ACU-4489, Acucela, Seattle, WA), a non-retinoid visual cycle modulator of the isomerase RPE65, showed a biological effect in patients affected by GA in a phase IIa trial (NCT01002950). Instead, Fenretinide (Sirion Therapeutics, Tampa, FL, USA), another visual cycle inhibitor, has not proved efficacy in treating patients affected by GA.

Another promising research field in the treatment of GA is stem cell therapy [50, 51]. Cell transplantation could lead to regeneration of RPE and photoreceptors that are compromised in GA. However, stem-cell-based therapy requires a long-term clinical trial and a multi-disciplinary approach.

\section{CONCLUSION}

Geographic atrophy, the late stage of age-related macular degeneration, is becoming a public health problem whose incidence is reaching great proportions [52]. Sunness et al. [12] reported that GA may affect up to $22 \%$ of the population in 90-year-old people. For this reason, there is a growing interest in finding new tools for the fast diagnosis and management of the disease and in finding new therapies for the prevention and treatment of GA.

In recent years, several new non-invasive tools have entered the clinical practice (e.g., FAF, OCT and OCT-A), allowing us to better follow up the natural course of GA patients. Nevertheless, several pathways concerning the pathogenesis of the disease should be investigated further.

Although no significant cure exists yet for GA, a healthy lifestyle and dietary pattern seem to play a crucial role in the prevention of GA. Furthermore, nutritional intervention with some specific supplementations (e.g., vitamins $\mathrm{C}$ and $\mathrm{E}$, beta-carotene, high dietary folate) seems to delay the progression of d-AMD, though this formula supplementation was not proven effective in GA patients. Currently, several drugs are under evaluation for the treatment of GA with promising results, but probably only a few of these will prove to have true efficacy and be available in clinical practice.

\section{ACKNOWLEDGEMENTS}

No funding or sponsorship was received for this study or publication of this article. All named authors meet the International Committee of Medical Journal Editors (ICMJE) criteria for authorship for this manuscript, take responsibility for the integrity of the work as a whole and have given final approval for the version to be published.

Disclosures. Francesco Bandello is a consultant for: Alcon (Fort Worth, Texas, USA), Alimera Sciences (Alpharetta, Georgia, USA), Allergan Inc. (Irvine, California, USA), Farmila-Thea (Clermont-Ferrand, France), Bayer Shering-Pharma (Berlin, Germany), Bausch And Lomb (Rochester, New York, USA), Genentech (San Francisco, California, USA), Hoffmann-La-Roche (Basel, Switzerland), NovagaliPharma (Évry, France), Novartis (Basel, Switzerland), Sanofi-Aventis (Paris, France), Thrombogenics (Heverlee, Belgium) and Zeiss (Dublin, California, USA). Giuseppe Querques is a consultant for: Alimera Sciences (Alpharetta, Georgia, USA), Allergan Inc. (Irvine, California, USA), Bayer Shering-Pharma (Berlin, Germany), Heidelberg (Germany), Novartis (Basel, Switzerland), Sandoz (Berlin, Germany) and Zeiss (Dublin, California, USA). Riccardo Sacconi, Eleonora Corbelli and Lea Querques have nothing to disclose.

Compliance with Ethics Guidelines. This article is based on previously conducted studies and does not involve any new studies of human or animal subjects performed by any of the authors. 
Open Access. This article is distributed under the terms of the Creative Commons Attribution-NonCommercial 4.0 International License (http://creativecommons.org/licenses/ by-nc/4.0/), which permits any noncommercial use, distribution, and reproduction in any medium, provided you give appropriate credit to the original author(s) and the source, provide a link to the Creative Commons license, and indicate if changes were made.

\section{REFERENCES}

1. Congdon N, O'Colmain B, Klaver CC, et al. Causes and prevalence of visual impairment among adults in the United States. Arch Ophthalmol. 2004;122:477-85.

2. Klein R, Klein BE, Lee KE, et al. Changes in visual acuity in a population over a 15 -year period: the Beaver Dam Eye Study. Am J Ophthalmol. 2006;142:539-49.

3. Erke MG, Bertelsen G, Peto T, Sjølie AK, Lindekleiv $\mathrm{H}$, Njølstad I. Prevalence of age-related macular degeneration in elderly Caucasians: the Tromsø Eye Study. Ophthalmology. 2012;119:1737-43.

4. Lim LS, Mitchell P, Seddon JM, et al. Age-related macular degeneration. Lancet. 2012;379:1728-38.

5. Klein R, Klein BE, Tomany SC, Moss SE. Ten-year incidence of age-related maculopathy and smoking and drinking: the Beaver Dam Eye Study. Am J Epidemiol. 2002;156:589-98.

6. Mares-Perlman JA, Brady WE, Klein R, et al. Dietary fat and age-related maculopathy. Arch Ophthalmol. 1995;113:743-8.

7. Klein R, Klein BE, Tomany SC, Cruickshanks KJ. The association of cardiovascular disease with the long-term incidence of age-related maculopathy: the Beaver Dam Eye Study. Ophthalmology. 2003; 110:1273-80.

8. Davis MD, Gangnon RE, Lee LY, et al. The Age-Related Eye Disease Study Research Group. The Age-Related Eye Disease Study severity scale for age-related macular degeneration: AREDS Report No. 17. Arch Ophthalmol. 2005;123:1484-98.

9. Ferris FL 3rd, Wilkinson CP, Bird A, Beckman Initiative for Macular Research Classification Committee, et al. Clinical classification of age-related macular degeneration. Ophthalmology. 2013;120:844-51.

10. Bird AC, Bressler NM, Bressler SB, et al. An international classification and grading system for age-related maculopathy and age-related macular degeneration. The International ARM Epidemiology Study Group. Surv Ophthalmol. 1995;39:367-74.

11. Buch H, Vinding T, Nielsen NV, et al. 14-year incidence progression and visual morbidity of age-related maculopaty: The Copenhagen City Eye Study. Ophthalmology. 2005;112:787-98.

12. Sunness JS, Margalit E, Srikurnaran D, et al. The long-term natural history of geographic atrophy from age-related macular degeneration: enlargement of atrophy and implications for interventional clinical trials. Ophthalmology. 2007;114:271-7.

13. Danis RP, Lavine JA, Domalpally A. Geographic atrophy in patients with advanced dry age-related macular degeneration: current challenges and future prospects. Clin Ophthalmol. 2015;9:2159-74.

14. Wang JJ, Buitendijk GH, Rochtchina E, et al. Genetic susceptibility, dietary antioxidants, and long-term incidence of age-related macular degeneration in two populations. Ophthalmology. 2014;121:667-75.

15. Chiu CJ, Chang ML, Zhang FF, et al. The relationship of major American dietary patterns to age-related macular degeneration. Am J Ophthalmol. 2014;158:118-27.

16. Clemons TE, Milton RC, Klein R, Seddon JM, Ferris FL 3rd. Age-Related Eye Disease Study Research Group. Risk factors for the incidence of Advanced Age-Related Macular Degeneration in the Age-Related Eye Disease Study (AREDS) AREDS report no. 19. Ophthalmology. 2005;112:533-9.

17. Merle BM, Silver RE, Rosner B, Seddon JM. Dietary folate, B vitamins, genetic susceptibility and progression to advanced nonexudative age-related macular degeneration with geographic atrophy: a prospective cohort study. Am J Clin Nutr. 2016;103:1135-44.

18. Schmitz-Valckenberg S, Fleckenstein M, Helb HM, Charbel Issa P, Scholl HP, Holz FG. In vivo imaging of foveal sparing in geographic atrophy secondary to age-related macular degeneration. Invest Ophthalmol Vis Sci. 2009;50:3915-21.

19. Holz FG, Bindewald-Wittich A, Fleckenstein M, Dreyhaupt J, Scholl HP, Schmitz-Valckenberg S, FAM-Study Group. Progression of geographic 
atrophy and impact of fundus autofluorescence patterns in age-related macular degeneration. Am J Ophthalmol. 2007;143:463-72.

20. Schmitz-Valckenberg S, Bindewald-Wittich A, Dolar-Szczasny J, Dreyhaupt J, Wolf S, Scholl HP, Holz FG. Fundus Autofluorescence in Age-Related Macular Degeneration Study Group. Correlation between the area of increased autofluorescence surrounding geographic atrophy and disease progression in patients with AMD. Investig Ophthalmol Vis Sci. 2006;47:2648-54.

21. Fleckenstein M, Charbel Issa P, Helb HM, et al. High-resolution spectral domain-OCT imaging in geographic atrophy associated with age-related macular degeneration. Investig Ophthalmol Vis Sci. 2008;49:4137-44.

22. Zweifel SA, Engelbert M, Laud K, Margolis R, Spaide RF, Freund KB. Outer retinal tubulation: a novel optical coherence tomography finding. Arch Ophthalmol. 2009;127:1596-602.

23. Cohen SY, Dubois L, Nghiem-Buffet S, et al. Retinal pseudocysts in age-related geographic atrophy. Am J Ophthalmol. 2010;150:211-7.

24. Querques G, Capuano V, Frascio P, Zweifel S, Georges A, Souied EH. Wedge-shaped subretinal hyporeflectivity in geographic atrophy. Retina. 2015;5:1735-42.

25. Querques G, Costanzo E, Miere A, Capuano V, Souied EH. Choroidal caverns: a novel optical coherence tomography finding in geographic atrophy. Investig Ophthalmol Vis Sci. 2016;57:2578-82.

26. Corbelli E, Sacconi R, De Vitis LA, et al. Choroidal round hyporeflectivities in geographic atrophy. PloS One. 2016;11:e0166968.

27. Waheed NK, Moult EM, Fujimoto JG, et al. Optical coherence tomography angiography of dry age related macular degeneration. Dev Ophthalmol. 2016;56:91-100.

28. Stein JD, Brown MM, Brown GC, et al. Quality of life with macular degeneration: perceptions of patients, clinicians, and community members. Br J Ophthalmol. 2003;87:8-12.

29. Applegate CA, Chao J, Zucherbrod AS, Sunness JS. Decline of reading rate over time in geographic atrophy from AMD. Investig Ophthalmol Vis Sci. 2003;44:1788.

30. Holz FG, Strauss EC, Schmitz-Valckenberg S, van Lookeren Campagne M. Geographic atrophy: clinical features and potential therapeutic approaches. Ophthalmology. 2014;121:1079-91.
31. Rovner BW, Casten RJ, Tasman WS. Effect of depression on vision function in age-related macular degeneration. Arch Ophthalmol. 2002;120:1041-4.

32. Williams RA, Brody BL, Thomas RG, Kaplan RM, Brown SI. The psychosocial impact of macular degeneration. Arch Ophthalmol. 1998;116:514-20.

33. Hong T, Mitchell P, Burlutsky G, Samarawickrama C, Wang JJ. Visual impairment and the incidence of falls and fractures among older people: longitudinal findings from the Blue Mountains Eye Study. Investig Ophthalmol Vis Sci. 2014;55:7589-93.

34. Mangione CM, Lee PP, Pitts J, Gutierrez P, Berry S, Hays RD. Psychometric properties of the National Eye Institute Visual Function Questionnaire (NEI-VFQ). NEI-VFQ Field Test Investigators. Arch Ophthalmol. 1998;116:1496-504.

35. Zarbin MA, Rosenfeld PJ. Pathway-based therapies for age-related macular degeneration: an integrated survey of emerging treatment alternatives. Retina. 2010;30:1350-67.

36. Age-Related Eye Disease Study Research Group. Risk factors associated with age-related macular degeneration: a case-control study in the Age-Related Eye Disease Study: AREDS report no. 3. Ophthalmolgy. 2000;107:2224-32.

37. Age-Related Eye Disease Study 2 Research Group. Lutein + zeaxanthin and omega-3 fatty acids for age-related macular degeneration: the Age-Related Eye Disease Study 2 (AREDS2) randomized clinical trial. JAMA. 2013;309:2005-15.

38. Ho E, Beaver LM, Williams DE, Dashwood RH. Dietary factors and epigenetic regulation for prostate cancer prevention. Adv Nutr. 2011;2:497-510.

39. WoldeMussie E, Ruiz G, Wijono M, et al. Neuroprotection of retinal ganglion cells by brimonidine in rats with laser-induced chronic ocular hypertension. Investig Ophthalmol Vis Sci. 2001;42:2849-55.

40. Allergan, Safety and efficacy of brimonidine intravitreal implant in patients with geographic atrophy due to age-related macular degeneration (AMD). In: ClinicalTrials.gov. https://clinicaltrials. gov/ct2/show/NCT00658619. Accessed 22 March 2017.

41. Tao W, Wen R, Goddard MB, et al. Encapsulated cell-based delivery of CNTF reduces photoreceptor degeneration in animal models of retinitis pigmentosa. Investig Ophthalmol Vis Sci. 2002;43:3292-8. 
42. Zhang K, Hopkins JJ, Heier JS, et al. Ciliary neurotrophic factor delivered by encapsulated cell intraocular implants for treatment of geographic atrophy in age-related macular degeneration. Proc Natl Acad Sci USA. 2011;108:6241-5.

43. Gehrs KM, Jackson JR, Brown EN, et al. Complement, age-related macular degeneration and a vision of the future. Arch Ophthalmol. 2010;128:349-58.

44. Anderson DH, Mullins RF, Hageman GS, et al. A role for local inflammation in the formation of drusen in the aging eye. Am J Ophthalmol. 2002;134:411-31.

45. Haines JL, Hauser MA, Schmidt S, et al. Complement factor $\mathrm{H}$ variant increases the risk of age-related macular degeneration. Science. 2005;308:419-21.

46. Yates JR, Sepp T, Matharu BK, et al. Complement C3 variant and the risk of age-related macular degeneration. N Engl J Med. 2007;357:553-61.

47. Augustin AJ, Diehm C, Grieger F, Bentz J. Alprostadil infusion in patients with dry age related macular degeneration: a randomized controlled clinical trial. Expert Opin Investig Drugs. 2013;22:803-12.

48. Metelitsina TI, Grunwald JE, DuPont JC, Ying GS. Effect of Viagra on the foveolar choroidal circulation of AMD patients. Exp Eye Res. 2005;81:159-64.

49. Resch H, Weigert G, Karl K, et al. Effect of systemic moxaverine on ocular blood flow in humans. Acta Ophthalmol. 2009;87:731-5.

50. Cho MS, Kim SJ, Ku SY, et al. Generation of retinal pigment epithelial cells from human embryonic stem cell-derived spherical neural masses. Stem Cell Res. 2012;9:101-9.

51. Buchholz DE, Hikita ST, Rowland TJ, et al. Derivation of functional retinal pigmented epithelium from induced pluripotent stem cells. Stem Cells. 2009;27:2427-34.

52. Klein R, Klein BE, Knudtson MD, Meuer SM, Swift $\mathrm{M}$, Gangnon RE. Fifteen-year cumulative incidence of age-related macular degeneration: the Beaver Dam Eye Study. Ophthalmology. 2007;114:253-62. 